\title{
Spiking patterns of neocortical L5 pyramidal neurons in vitro change with temperature
}

\author{
Tristan Hedrick and Jack Waters* \\ Department of Physiology, Feinberg School of Medicine, Northwestern University, Chicago, IL, USA
}

\section{Edited by:}

Dieter Wicher, Max Planck Institute for

Chemical Ecology, Germany

Reviewed by:

Matthew Nolan, The University of

Edinburgh, UK

Alon Korngreen, Bar-Ilan University,

Israel

${ }^{*}$ Correspondence:

Jack Waters, Department of

Physiology, Feinberg School of

Medicine, Northwestern University,

303 East Chicago Avenue, Chicago, IL

60611, USA.

e-mail: jackwaters@northwestern.edu
A subset of pyramidal neurons in layer 5 of the mammalian neocortex can fire action potentials in brief, high-frequency bursts while others fire spikes at regularly spaced intervals. Here we show that individual layer 5 pyramidal neurons in acute slices from mouse primary motor cortex can adopt both regular and burst spiking patterns. During constant current injection at the soma, neurons displayed a regular firing pattern at $36-37^{\circ} \mathrm{C}$, but switched to burst spiking patterns upon cooling the slice to $24-26^{\circ} \mathrm{C}$. This change in firing pattern was reversible and repeatable and was independent of the somatic resting membrane potential. Hence these spiking patterns are not inherent to discrete populations of pyramidal neurons and are more interchangeable than previously thought. Burst spiking in these neurons is the result of electrical interactions between the soma and distal apical dendritic tree. Presumably the interactions between soma and distal dendrite are temperature-sensitive, suggesting that the manner in which layer 5 pyramidal neurons translate synaptic input into an output spiking pattern is fundamentally altered at sub-physiological temperatures.

Keywords: pyramidal neuron, neocortex, layer 5, spiking pattern, burst, temperature

\section{INTRODUCTION}

Many neurons in the mammalian CNS fire action potentials in brief, high-frequency bursts. Bursts may be a more reliable mechanism of information transfer than single action potentials at synapses at which short-term facilitation of transmitter release can occur (Lisman, 1997).

Most pyramidal neurons in neocortex exhibit a regular spiking pattern, firing action potentials at constant frequency during maintained suprathreshold current injection at the soma. A subset of pyramidal neurons fire discrete clusters of 2-6 action potentials at regular intervals during constant current injection (Connors et al., 1982; McCormick et al., 1985; Agmon and Connors, 1989; Chagnac-Amitai et al., 1990; Mason and Larkman, 1990). The somata of these "intrinsically bursting" neurons are found only in layer 5 (Connors et al., 1982; McCormick et al., 1985; Agmon and Connors, 1989; Chagnac-Amitai et al., 1990; Mason and Larkman, 1990) and in these neurons bursting results from the activation of sodium and calcium conductances in the apical dendrite (Silva et al., 1991; Schwindt and Crill, 1999; Williams and Stuart, 1999; Larkum et al., 2001; Larkum and Zhu, 2002).

Within layer 5, regularly spiking and intrinsically bursting neurons co-exist. There is evidence that regularly spiking and intrinsically bursting neurons in layer 5 are morphologically distinct from each other (Chagnac-Amitai et al., 1990; Mason and Larkman, 1990), suggesting that spiking pattern could be used to differentiate between two discrete classes of layer 5 pyramidal neurons.

Here we show that individual layer 5 pyramidal neurons in acute slices from mouse primary motor cortex can adopt both regular and burst spiking patterns during constant current injection at the soma, changing from regularly spiking to burst firing upon cooling the slice from 36 to $37^{\circ} \mathrm{C}$ toward room temperature. Hence these spiking patterns are more interchangeable than previously thought.

\section{MATERIALS AND METHODS}

All experiments and procedures were approved by the Northwestern University Institutional Animal Care and Use Committee (IACUC).

\section{SLICE PREPARATION}

P42-P54 C57BL-6 mice were anesthetized using isoflurane (3\%, inhaled) and decapitated. The brain was quickly removed into icecold artificial cerebrospinal fluid (ACSF): $125 \mathrm{mM} \mathrm{NaCl}, 2.5 \mathrm{mM}$ $\mathrm{KCl}, 1.25 \mathrm{mM} \mathrm{NaH}_{2} \mathrm{PO}_{4}, 20 \mathrm{mM} \mathrm{NaHCO}_{3}, 5 \mathrm{mM}$ HEPES, $25 \mathrm{mM}$ glucose, $1 \mathrm{mM} \mathrm{CaCl}_{2}, 2 \mathrm{mM} \mathrm{MgCl}_{2}, \mathrm{pH} 7.3$, gassed with $95 \% \mathrm{O}_{2} / 5 \%$ $\mathrm{CO}_{2}$. Two hundred micrometer-thick parasagittal slices were cut using a vibrating microslicer (Vibratome, St. Louis, MO, USA). Slices were held in ACSF at $37^{\circ} \mathrm{C}$ for $5-15 \mathrm{~min}$ and thereafter at room temperature until use.

\section{ELECTROPHYSIOLOGY}

Slices were transferred to the stage of an upright microscope (Olympus BX51) and continuously perfused with ACSF gassed with $95 \% \mathrm{O}_{2} / 5 \% \mathrm{CO}_{2}$ and warmed to $35-37^{\circ} \mathrm{C}$. Whole-cell recordings were obtained from pyramidal neurons in layer 5 of primary motor cortex under visual guidance with a $\times 40 /$ NA 0.8 or $\times 20$ /NA 1.0 water-immersion objective and infra-red difference interference contrast optics. Layer 5 pyramidal neurons were identified by their large, pyramidal somata, located 720-960 $\mu \mathrm{m}$ from the pial edge of the slice (seven neurons), their characteristic firing patterns and large apical dendritic trees, visible by fluorescence microscopy once filled with indicator. Whole-cell recording pipettes were 4-8 $\mathrm{M} \Omega$ when filled with intracellular solution: $135 \mathrm{mM}$ K-gluconate, $4 \mathrm{mM} \mathrm{KCl}, 10 \mathrm{mM}$ HEPES, $10 \mathrm{mM}$ $\mathrm{Na}_{2}$-phosphocreatine, $4 \mathrm{mM} \mathrm{Mg}$-ATP, $0.3 \mathrm{mM} \mathrm{Na}_{2}$-GTP, $0.2 \%$ (w/v) biocytin, $10 \mu \mathrm{M}$ Alexa 594, pH 7.3. Signals were recorded 
with an Axoclamp-2A amplifier (Molecular Devices, Sunnyvale, CA, USA), National Instruments A-to-D boards and Labview software written by Jack Waters (National Instruments, Austin, TX, USA).

\section{MEASUREMENT AND CONTROL OF TEMPERATURE}

Artificial cerebrospinal fluid was warmed with a thermistor-based in-line solution heater, placed a few inches from the slice. The temperature of the solution was monitored upon entry to the perfusion chamber, a few millimeters from the slice, and maintained at $35-37^{\circ} \mathrm{C}$ by a feedback circuit and temperature controller (TC-324B; Warner Instruments, Hamden, CT, USA). Flow rate was $\sim 3-6 \mathrm{ml} / \mathrm{min}$. The temperature of the ACSF under the objective was verified with a BAT-12 Microprobe Thermometer (Physitemp Instruments, Clifton, NJ, USA), using a small 24-gage polyurethane coated wire probe with polyester insulated thermocouple bead (IT-24P; maximum tip diameter $230 \mu \mathrm{m}$ ), which was placed under the microscope objective. The temperature of ACSF under the objective, measured using the IT-24P probe, was consistently no more than $0.5^{\circ} \mathrm{C}$ cooler than the temperature of the ACSF entering the perfusion chamber, measured by the TC-324B temperature controller.

\section{ANALYSIS}

Analysis was performed using routines written by Jack Waters in IgorPro v6.0 (Wavemetrics, Lake Oswego, OR, USA). Physiological properties were measured in bridge mode, using $300 \mathrm{~ms}$ square current injections.

Spiking patterns were assessed where the neuron was given a suprathreshold $300 \mathrm{~ms}$ current injection at the soma which resulted in 4-7 spikes. A spiking pattern was defined as regular if all interspike intervals (ISIs) throughout the spike train were within $15 \%$ of the mean ISI. Where the ISIs fell outside of this range, the spiking pattern was described as bursting.

$V-I$ relationships were derived from the steady-state voltage during 300 ms current steps and were fit with the following relationship (Waters and Helmchen, 2006):

$\Delta V=R_{N, 0} \Delta I+c_{A R} \Delta I^{2}$

where $R_{N}$ is the resting input resistance (slope at $I=0$ ) and $c_{A R}$ is a quadratic coefficient which describes the curvature of the $V-I$ relationship.

Voltage sag was estimated as the ratio of steady-state and peak voltages during the 300 -ms current step (sag ratio). The membrane time constant was determined by fitting an exponential to the rising phase of the voltage response during the current step.

Action potential threshold was defined as the point at which the first temporal derivative of the voltage $(\mathrm{d} V / \mathrm{d} t)$ first exceeded $50 \mathrm{mV} / \mathrm{ms}$. Action potential amplitude was measured from threshold. Action potential half width was measured at half the amplitude. Action potential rise and decay times were measured as the time intervals between 10 and $90 \%$ of the voltage difference between threshold and peak. Rheobase was defined as the minimum amount of current required to evoke spiking.

Statistical comparisons were performed using the Wilcoxon matched-pairs signed-ranks test or paired $t$-test in Graphpad Instat 3.06 (Graphpad Software, La Jolla, CA, USA).

\section{RESULTS \\ REVERSIBLE CHANGE IN SPIKING PATTERN WITH TEMPERATURE}

We obtained whole-cell recordings from the somata of layer 5 pyramidal neurons in primary motor cortex in acute slices from adult mice. Perfusing ACSF was initially maintained at $36-37^{\circ} \mathrm{C}$. At this temperature, all neurons displayed regular spiking patterns during depolarizing current injections (Figure $1 ; n=10$ neurons). A spiking pattern was defined as regular if ISIs throughout the spike train were within $15 \%$ of the mean ISI.

The temperature of the ACSF was then permitted to decline, and this resulted in a change to a burst spiking pattern (Figures 1 and $2 \mathrm{~A}$ ). At $24-26^{\circ} \mathrm{C}$, in all 10 neurons the first ISI (ISI ${ }_{1-2}$ ) was invariably $>15 \%$ shorter than the mean, reflecting high-frequency firing during an initial burst of spikes (Figure 2B).

Like previous authors we distinguished between two burst spiking patterns: "intrinsic" or "strong" bursting, in which all spikes were clustered into brief, high-frequency bursts, each containing $2-5$ spikes and separated by a prolonged hyperpolarization (Connors et al., 1982; Williams and Stuart, 1999); and weak bursting, in which an initial burst of $2-5$ spikes at high frequency was followed by regular spiking (Williams and Stuart, 1999). At $24-26^{\circ} \mathrm{C}$, four neurons adopted strong burst spiking patterns, with bursts of 2-4 spikes. In these neurons the inter-spike interval between third and fourth action potentials in the train $\left(\mathrm{ISI}_{3-4}\right.$ ) remained short (Figure 2C). The remaining six neurons fired in a weak bursting pattern at $24-26^{\circ} \mathrm{C}$, with a single burst of $2-4$ high-frequency spikes followed by a regular spiking pattern. During weak burst spiking $\mathrm{ISI}_{3-4}$ was comparable to that during regular spiking at $36-37^{\circ} \mathrm{C}$ (Figure 2C).

Most neurons changed their spiking patterns with larger-amplitude current injections, as in previous publications (Agmon and Connors, 1989; Mason and Larkman, 1990; Williams and Stuart, 1999). During larger-amplitude current injections at $36-37^{\circ} \mathrm{C}$, two neurons fired a doublet of high-frequency spikes before adopting a regular spiking pattern. The other eight neurons maintained a regular spiking pattern in response to current of all amplitudes. At $24-26^{\circ} \mathrm{C}$, all neurons maintained bursting patterns in response to all current injections. During large current injections the strongly bursting neurons began with an initial burst of 2-4 spikes which was followed with regular spiking. In weakly bursting neurons, with increasing current the number of spikes in the initial burst increased to $\geq 4$ spikes and the subsequent action potentials remained regularly spaced.

The transition from regular spiking to bursting was reversible and reproducible. Upon re-warming the slice, the neuron returned to a regular spiking pattern (Figure 1). Furthermore, a subsequent decline in temperature (to $24-26^{\circ} \mathrm{C}$ ) and return to $36-37^{\circ} \mathrm{C}$ again resulted in a reversible transition to bursting and back to regular spiking (Figure 1).

\section{REVERSIBLE CHANGES IN OTHER INTRINSIC PROPERTIES}

The action potential waveform also changed with temperature and spiking pattern. The amplitude and half width of the first action potential were greater and broader, respectively, during bursting at $24-26^{\circ} \mathrm{C}$ than at physiological temperature (Figures $\mathbf{3 A}, \mathbf{B}$; $P<0.05$ ), whereas voltage threshold for the first spike was unchanged (Figures 3A,B; $P>0.05$ ). During regular or weak burst spiking there 


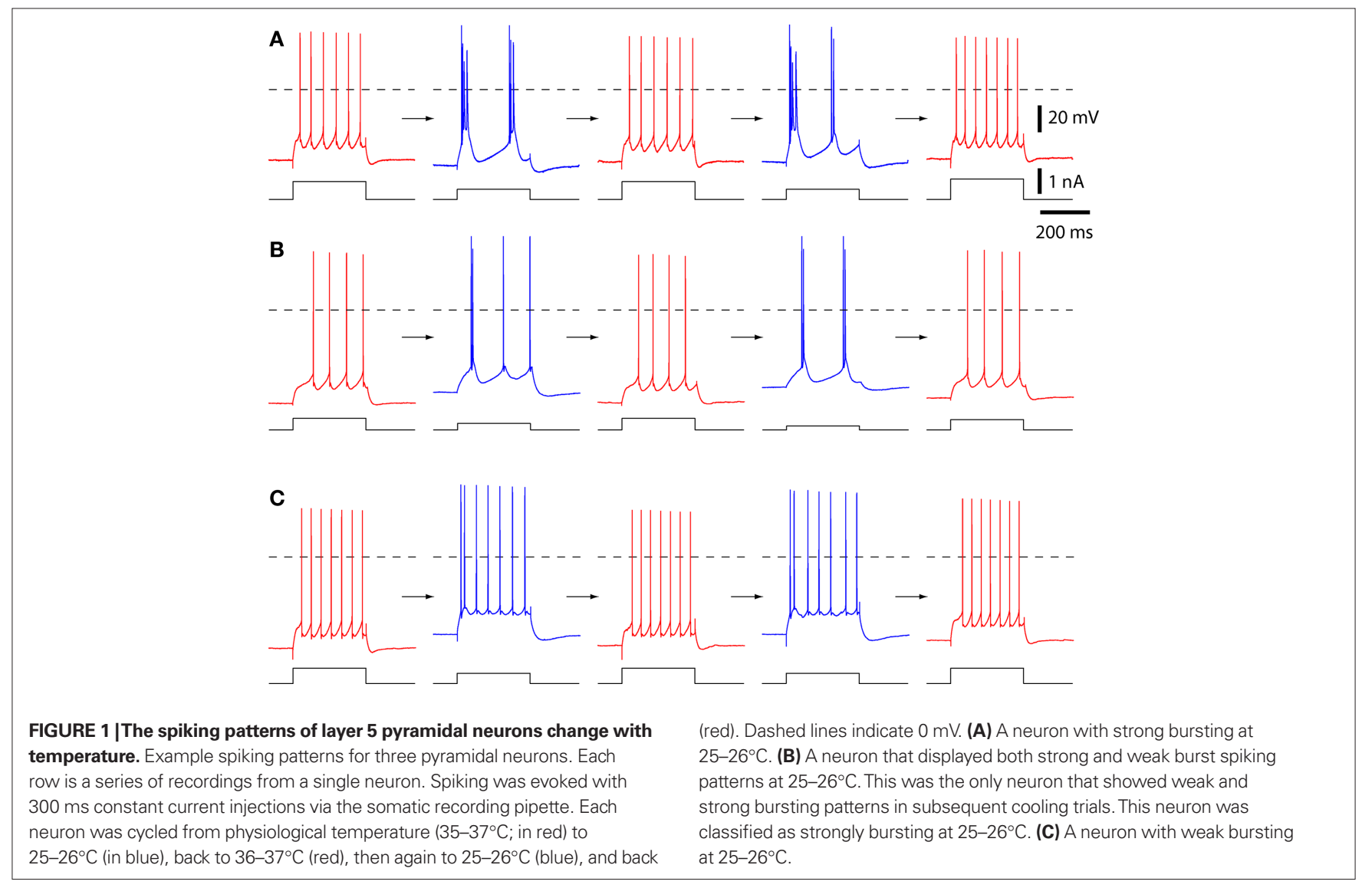

was little change in action potential threshold, amplitude, or half width during the train of spikes. In contrast, threshold became more depolarized, amplitude was reduced, and spike became broader during a strong burst (Figures 3A,B).

There was no difference in resting membrane potential at physiological and lower temperatures $(P>0.05$; Figure 3C). However, membrane sag increased $\sim 6 \%$ at $24-26^{\circ} \mathrm{C}(P<0.05$; Figure $3 \mathrm{C})$. Resting input resistance and membrane time constant were both approximately doubled at $24-26^{\circ} \mathrm{C}$ (each $P<0.05$; Figure $3 \mathrm{C}$ ). Membrane rectification was increased to approximately three times the value at physiological temperature $(P<0.05$; Figure $3 \mathrm{C})$. Rheobase was approximately halved at $24-26^{\circ} \mathrm{C}(P<0.05$; Figure 3C).

\section{SOMATIC DEPOLARIZATION DOES NOT MIMIC THE EFFECT OF TEMPERATURE ON SPIKING PATTERN}

Although the mean resting membrane potential did not change with temperature, in some neurons there was a reversible shift in resting membrane potential with temperature (Figure 4). In individual neurons, cooling to $24-26^{\circ} \mathrm{C}$ could cause depolarization of up to $10 \mathrm{mV}$ and hyperpolarization of up to $9 \mathrm{mV}$. We therefore considered whether such a change in membrane potential could cause a switch in spiking pattern. To alter membrane potential, we injected positive and negative holding currents into six neurons, three of which fired strong bursts at $24-26^{\circ} \mathrm{C}$ and three of which fired weak bursts. The firing patterns of all six neurons remained unchanged (depolarizations of $10.7 \pm 0.5 \mathrm{mV}$ at $24-26^{\circ} \mathrm{C}$ and
$8.7 \pm 1.0 \mathrm{mV}$ at $36-37^{\circ} \mathrm{C}$; hyperpolarizations of $9.5 \pm 0.5 \mathrm{mV}$ at $24-26^{\circ} \mathrm{C}$ and $8.6 \pm 0.9 \mathrm{mV}$ at $36-37^{\circ} \mathrm{C}$ ). Hence a shift in somatic membrane potential cannot account for the change in spiking pattern with temperature.

\section{DISCUSSION}

We have shown that layer 5 neocortical pyramidal neurons in primary motor neocortical slices typically adopt a regular spiking pattern in response to constant somatic current injection at physiological temperatures, but spike in bursts at lower temperatures. Hence each individual layer 5 pyramidal neuron can adopt either spiking pattern in response to constant somatic current injection and even neurons which are able to spike in bursts may commonly display regular spiking patterns at physiological temperatures.

\section{TEMPERATURE SENSITIVITY OF INTRINSIC MEMBRANE PROPERTIES}

Intrinsic membrane properties also changed with temperature: resting input resistance, membrane time constant, curvature of the $I-V$ relationship all increased approximately two- to three-fold with the decline in temperature to $24-26^{\circ} \mathrm{C}$. Similar effects have previously been observed in hippocampal and neocortical pyramidal neurons in slice preparations from various species, including an increase in input resistance of $\sim 50-100 \%$ over a similar temperature range to that studied here (Thompson et al., 1985; Shen and Schwartzkroin, 1988; Volgushev et al., 2000; Trevelyan and Jack, 2002; Lee et al., 2005). 

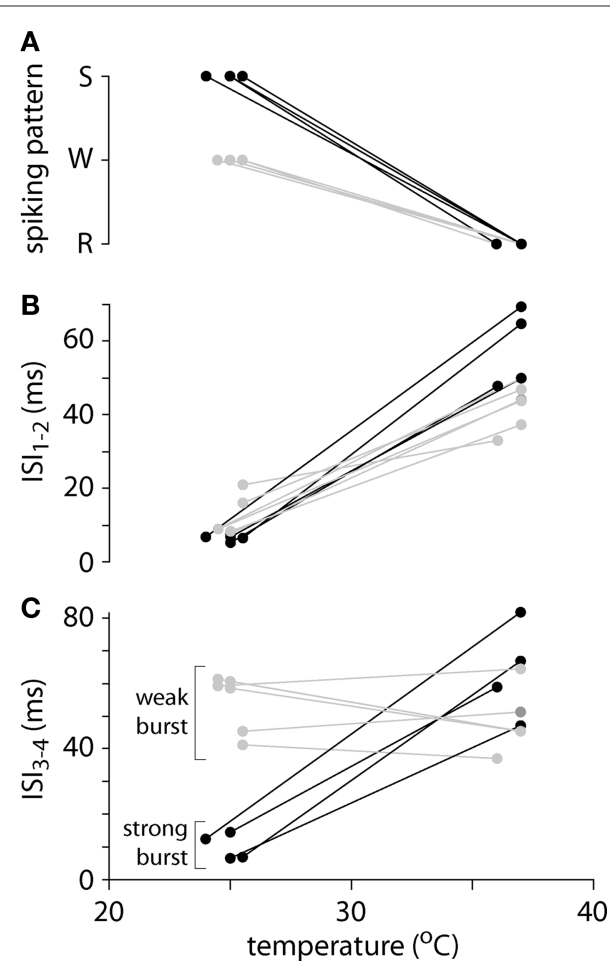

FIGURE 2 | Spiking patterns and inter-spike intervals at low and physiological temperatures. (A) Summary of spiking patterns for 10 layer 5 pyramidal neurons at low and high temperatures. All neurons display regular spiking (R) at physiological temperatures and weak (W; gray) or strong (S; black) burst spiking at lower temperatures. (B) Inter-spike interval between the first and second spike $\left(\mathrm{ISI}_{1-2}\right)$ as a function of temperature for 10 pyramidal neurons. (C) Inter-spike interval between the third and fourth spike $\left(\mathrm{ISI}_{3-4}\right)$ as a function of temperature for 10 pyramidal neurons. These neurons fall into two groups: four with strong burst spiking patterns (black), in which $\mathrm{ISI}_{3-4}$ is comparable to $|S|_{1-2}$, and six with weak burst spiking patterns (gray), in which $\mathrm{ISI}_{3-4}$ is comparable at the two temperatures.

We observed no change in mean resting membrane potential in across the population of neurons examined, but there were substantial changes in resting membrane potentials of up to $10 \mathrm{mV}$ in some neurons. Other authors also report a mixture of effects of temperature on resting membrane potential in both hippocampus and cortex, with some authors reporting significant $(10-15 \mathrm{mV})$ depolarization following a reduction in temperature in both hippocampus and neocortex (Shen and Schwartzkroin, 1988; Volgushev et al., 2000; Trevelyan and Jack, 2002) and reporting no effect of temperature on resting membrane potential (Thompson et al., 1985; Lee et al., 2005).

\section{TEMPERATURE AND THE MECHANISM OF BURSTING IN LAYER 5 PYRAMIDAL NEURONS}

Burst spiking in layer 5 neocortical pyramidal neurons results from the activation of sodium and calcium currents in the distal apical dendrite. Activation of these currents can generate a mixed sodium/ calcium-based dendritic spike in the dendrite, which causes prolonged depolarization of the axon initial segment, resulting in a burst of spikes (Schiller et al., 1997; Schwindt and Crill, 1999; Williams and Stuart, 1999). Presumably increasing temperature limits activation of sodium and calcium currents in the distal dendrite or the ability
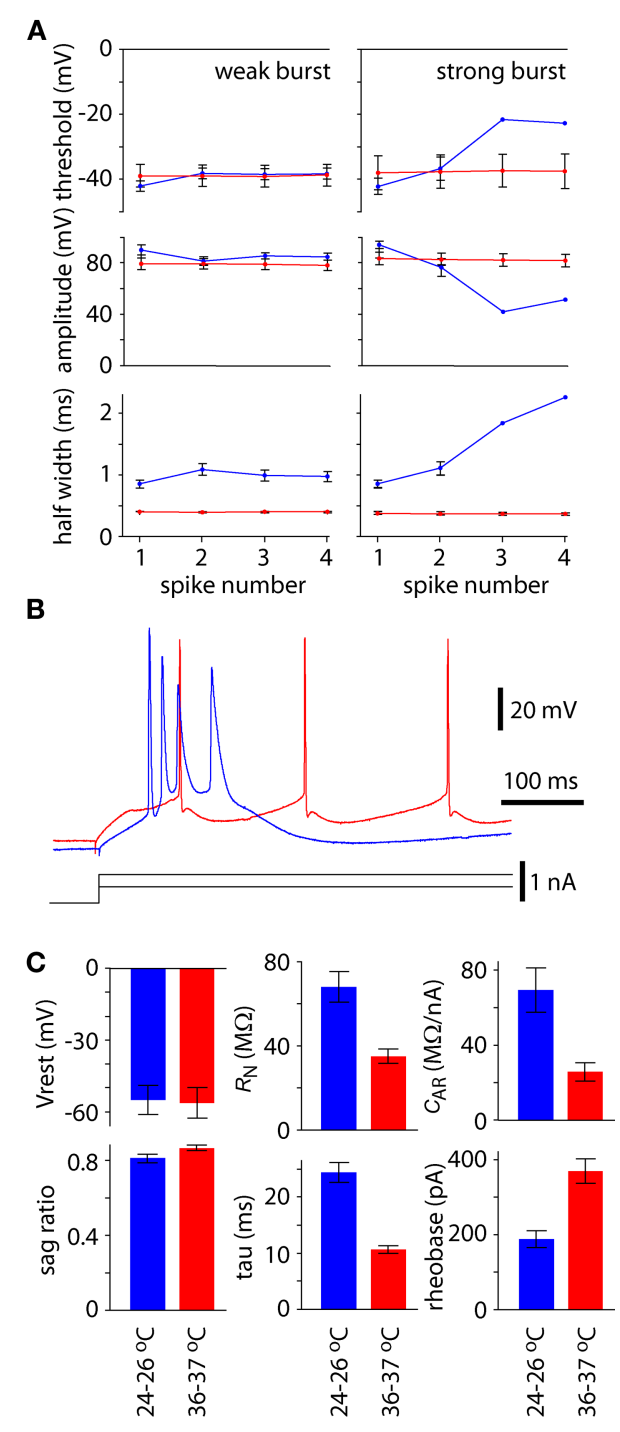

FIGURE 3 | Effects on temperature on spike waveform and membrane parameters. (A) Spike threshold, amplitude and half width for the first four spikes during $300 \mathrm{~ms}$ constant current injection at $25-26^{\circ} \mathrm{C}$ (blue) and $36-37^{\circ} \mathrm{C}$ (red). Results were pooled separately for neurons that displayed strong bursting patterns at $25-26^{\circ} \mathrm{C}$ and weak bursting patterns at $25-26^{\circ} \mathrm{C}$. Points represent the mean $( \pm$ SEM) from four neurons with strong bursting patterns and six with weak bursting patterns at $25-26^{\circ} \mathrm{C}$. (B) Example recording to illustrate the contrast in spike threshold, amplitude and half width for a single neuron at when displaying regular spiking at physiological temperature (red) and string bursting at lower temperature (blue). (C) Effects of temperature on resting membrane potential $\left(V_{\text {rest }}\right)$, membrane sag, input resistance $\left(R_{N}\right)$, membrane time constant (tau), anomalous rectification $\left(c_{A R}\right)$ and rheobase. Each bar represents the mean \pm SEM from 10 neurons.

of these currents to affect spiking. In this context it is interesting that the membrane time constant and input resistance of layer 5 neurons both approximately doubled when the temperature decreased to $24-26^{\circ} \mathrm{C}$. An increase in membrane time constant might prolong the depolarization that results from activation of sodium and calcium currents. An increase in membrane resistance would increase the space constant of the dendrite, facilitating the spread of current from soma to dendrite and vice versa. A change in electrical coupling 


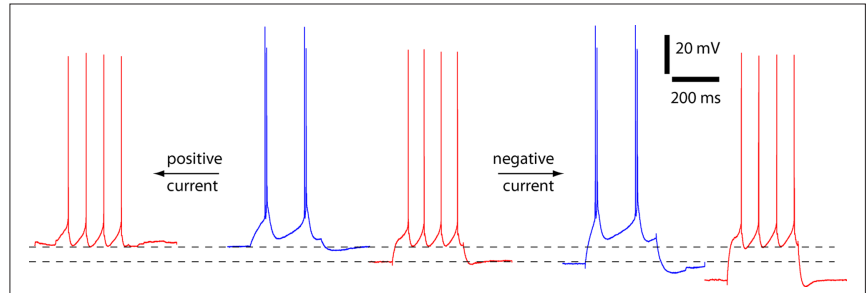

FIGURE 4 | Spiking pattern unaltered by somatic depolarization or hyperpolarization. An example of an experiment to assess the effects of membrane potential on spiking pattern at physiological and lower temperatures. The neuron changes from regular spiking to strong burst spiking as a result of a decline in temperature from $37^{\circ} \mathrm{C}$ (red) to $25.5^{\circ} \mathrm{C}$ (blue). In this neuron the decline in temperature was accompanied by depolarization of the resting membrane potential from -65 to $-57 \mathrm{mV}$. Somatic current injection was used to depolarize and hyperpolarize the membrane potential. At both temperatures the spiking pattern was unaffected by somatic current injection.

might account for the effects of temperature on spiking pattern, with the flow of electrical signals between soma and distal apical dendrite being inhibited at warmer temperatures.

Alternatively lower temperatures might favor bursting by causing depolarization of the distal apical dendrite, which pushes the dendrite toward the voltage threshold for a dendritic spike (Williams and Stuart, 1999; Larkum et al., 2001). In our experiments, depolarization of the neuron had no effect on the spiking pattern, but we depolarized the neuron by somatic current injection, which will have an extremely limited effect on the membrane potential in the distal dendrites (Williams and Mitchell, 2008).

\section{DISTINCTION BETWEEN REGULARLY SPIKING AND BURSTING LAYER 5 NEURONS}

Many authors have investigated the spiking patterns of layer 5 pyramidal neurons and concluded that the population is mixed, with some neurons firing in bursts in response to constant current injection and some neurons adopting a regular spiking pattern (Connors et al., 1982; McCormick et al., 1985; Agmon and Connors, 1989; Chagnac-Amitai et al., 1990; Mason and Larkman, 1990; Schwindt and Crill, 1999; Williams and Stuart, 1999). Spiking patterns have been correlated to morphological characteristics, including the diameter of the apical dendritic trunk and size of the apical dendritic tree (Mason and Larkman, 1990). These studies suggest that bursting is an intrinsic property of a morphologically distinct subset of layer 5 pyramidal neurons. Here we show that individual layer 5 pyramidal neurons can adopt both spiking patterns.

The proportions of neurons that spike in bursting and with regular patterns differ between previous publications. For example, Chagnac-Amitai et al. (1990) reported that $\sim 50-60 \%$ of layer 5 pyramidal neurons in rat somatosensory cortex spike in bursts, whereas Schwindt and Crill (1999) reported a much lower proportion of bursting neurons $(-33 \%)$ in the same brain region. Some of the disparity in the literature might result from species or age differences or from slightly different classifications of bursting behavior. Selection bias might also contribute. For example, bursting neurons may have larger somata than regularly spiking layer 5 pyramidal neurons (Chagnac-Amitai et al., 1990; Larkman and Mason, 1990). Hence a bias toward larger somata might lead to a higher proportion of bursting neurons. We performed no morphological analyses in our study, but bursting occurred in all of our recordings, raising the possibility that the neurons included in our study may represent a subset of layer 5 pyramidal neurons.

The temperature-sensitivity of spiking patterns observed here might help explain the disparity in the proportion of neurons classified as bursting by different authors. In these previous reports, recordings were obtained from slices maintained over a narrow range of temperatures: $32^{\circ} \mathrm{C}$ (Agmon and Connors, 1989), 33 ${ }^{\circ} \mathrm{C}$ (Schwindt and Crill, 1999), $35^{\circ} \mathrm{C}$ (Chagnac-Amitai et al., 1990), $34-36^{\circ} \mathrm{C}$ (Williams and Stuart, 1999), $37^{\circ} \mathrm{C}$ (Connors et al., 1982), temperature not stated (McCormick et al., 1985; Mason and Larkman, 1990). The method and accuracy of temperature measurements are rarely stated in these or other slice physiology studies and even small inaccuracies of a few degrees Celsius might alter the proportion of layer 5 neurons that spike in bursts. Hence in addition to a possible selection bias, here we add temperature as another factor that might have influenced the proportion of bursting neurons in this and previous studies, as relatively subtle differences in temperature could readily account for much of the variability between studies.

The idea that a single layer 5 pyramidal neuron can change its spiking pattern is not new. For example, current injection into the proximal apical dendrite favors burst spiking by enhancing the interaction between soma and distal apical dendrite and this has led to the suggestion that synaptic activity in the proximal apical dendritic tree can control the neuron's spiking pattern (Larkum et al., 2001). It has also been suggested that individual layer 5 pyramidal neurons may switch between regular and burst spiking patterns in vivo, again depending on the patterns of ongoing synaptic activation (Steriade, 2004). Here we show that the spiking patterns of layer 5 pyramidal neurons are even more flexible than previously thought: even in the absence of synaptic activity pyramidal neurons can adopt different spiking patterns in response to the same stimulus.

\section{LAYER 5 PYRAMIDAL NEURONS AS CELLULAR COINCIDENCE DETECTORS}

Layer 5 pyramidal neurons can act as cellular coincidence detectors, detecting, and responding to coincident activity in deep and superficial layers of the neocortex (Larkum et al., 1999). Burst spiking is central to this role. At physiological temperatures, layer 5 pyramidal neurons adopt regular spiking patterns in response to synaptic activity in their proximal dendrites, which reside in deep layers of the neocortex. Coincident activation of the distal apical dendrite, in superficial layers of the neocortex, may generate a burst of spikes (Larkum et al., 1999). We have shown that layer 5 pyramidal neurons spike in bursts in response to somatic input alone at $24-26^{\circ} \mathrm{C}$. Presumably under these conditions this form of coincidence detection is lost. Since cellular coincidence detection is probably a fundamental function and perhaps the principal task of these neurons, our results suggest that layer 5 pyramidal neurons are incapable of performing one of their most important physiological functions at sub-physiological temperatures.

\section{ACKNOWLEDGMENTS}

We thank Becky Imhoff for technical assistance and Abigail Kalmbach for discussions and Charles Anderson, Abigail Kalmbach, Taro Kiritani, and Patrick Sheets critical reading of the manuscript. We thank the National Institute of Mental Health (5T32MH06756408 and 5R21MH085117-02) and the Brain Research Foundation (BRF SG 2010-13) for funding. 


\section{REFERENCES}

Agmon, A., and Connors, B. W. (1989). Repetitive burst-firing neurons in the deep layers of mouse somatosensory cortex. Neurosci. Lett. 99, 137-141.

Chagnac-Amitai, Y., Luhmann, H. J., and Prince, D. A. (1990). Burst generating and regular spiking layer 5 pyramidal neurons of rat neocortex have different morphological features. J. Comp. Neurol. 296, 598-613.

Connors, B. W., Gutnick, M. J., and Prince, D. A. (1982). Electrophysiological properties of neocortical neurons in vitro. J. Neurophysiol. 48, 1302-1320.

Larkman, A., and Mason, A. (1990). Correlations between morphology and electrophysiology of pyramidal neurons in slices of rat visual cortex. I. Establishment of cell classes. J. Neurosci. 10, 1407-1414.

Larkum, M. E., and Zhu, J. J. (2002). Signaling of layer 1 and whiskerevoked $\mathrm{Ca}_{2}^{+}$and $\mathrm{Na}^{+}$action potentials in distal and terminal dendrites of rat neocortical pyramidal neurons in vitro and in vivo. J. Neurosci. 22, 6991-7005.

Larkum, M. E., Zhu, J. J., and Sakmann, B. (1999). A new cellular mechanism for coupling inputs arriving at different cortical layers. Nature 398, 338-341.

Larkum, M. E., Zhu, J. J., and Sakmann, B. (2001). Dendritic mechanisms underlying the coupling of the dendritic with the axonal action potential initiation zone of adult rat layer 5 pyramidal neurons. J. Physiol. 533.2, 447-466.

Lee, J. C. F., Callaway, J. C., and Foehring, R. C. (2005). Effects of temperature on calcium transients and $\mathrm{Ca}^{+}$dependent after hyperpolarizations in neocortical pyramidal neurons. J. Neurophysiol. 93, 2012-2020.

Lisman, J. E. (1997). Bursts as a unit of neural information: making unreliable synapses reliable. Trends Neurosci. 20, 38-43.

Mason, A., and Larkman, A. (1990). Correlations between morphology and electrophysiology of pyramidal neurons in slices of rat visual cortex II. Electrophysiology. J. Neurosci. 70, 1415-1428.

McCormick, D. A., Connors, B. W. Lighthall, J. W., and Prince, D. A. (1985). Comparative electrophysiology of pyramidal and sparsely spiny stellate neurons of the neocortex. $J$. Neurophysiol. 54, 782-806.

Schiller, J., Schiller, Y., Stuart, G., and Sakmann, B. (1997). Calcium action potentials restricted to distal apical dendrites of rat neocortical pyramidal neurons. J. Physiol. 505.3, 605-616.

Schwindt, P., and Crill, W. (1999). Mechanisms underlying burst and regular spiking evoked by dendritic depolarization in layer 5 cortical pyramidal neurons. J. Neurophysiol. 81, 1341-1354.

Shen, K., and Schwartzkroin, P. A. (1988) Effects of temperature alterations on population and cellular activities in hippocampal slices from mature and immature rabbit. Brain Res. 475, 305-316.

Silva, L. R., Amitai, Y., and Connors, B. W. (1991). Intrinsic oscillations of neocortex generated by layer 5 pyramidal neurons. Science 251 , 432-435.

Steriade, M. (2004). Neocortical cell classes are flexible entities. Nat. Rev. Neurosci. 5, 121-134.

Thompson, S. M., Masukawa, L. M., and Prince, D. A. (1985). Temperature dependence of intrinsic membrane properties and synaptic potentials in hippocampal CA1 neurons in vitro. $J$. Neurosci. 5, 817-824.

Trevelyan, A. J., and Jack, J. (2002). Detailed passive cable models of layer $2 / 3$ pyramidal cells in rat visual cortex at different temperatures. J. Physiol. 539.2, 623-636.

Volgushev, M., Vidyasagar, T. R., Chistiakova, M., Yousef, T., and Eysel, U. T. (2000). Membrane properties and spike generation in rat visual cortical cells during reversible cooling. J. Physiol. 522.1, 59-76.

Waters, J., and Helmchen, F. (2006). Background synaptic activity is sparse in neocortex. J. Neurosci. 26, 8267-8277.

Williams, S. R., and Mitchell, S. J. (2008). Direct measurement of somatic voltage clamp errors in central neurons. Nat. Neurosci. 7, 790-798.

Williams, S. R., and Stuart, G. J. (1999). Mechanisms and consequences of action potential burst firing in rat neocortical pyramidal neurons. J. Physiol. 521.2, 467-482.

Conflict of Interest Statement: The authors declare that the research was conducted in the absence of any commercial or financial relationships that could be construed as a potential conflict of interest.

Received: 22 December 2010; paper pending published: 05 January 2011; accepted: 06 January 2011; published online: 25 January 2011.

Citation: Hedrick T and Waters J (2011) Spiking patterns of neocortical L5 pyramidal neurons in vitro change with temperature. Front. Cell. Neurosci. 5:1. doi: 10.3389/fncel.2011.00001

Copyright (c) 2011 Hedrick and Waters. This is an open-access article subject to an exclusive license agreement between the authors and Frontiers Media SA, which permits unrestricted use, distribution, and reproduction in any medium, provided the original authors and source are credited. 